Health Environments Research \& Design 6, no. 4 (2012): 101-126.

THE QUESTION OF KNOWLEDGE IN EVIDENCE-BASED DESIGN FOR HEALTH CARE FACILITIES: LIMITATIONS AND SUGGESTIONS

\author{
Author: \\ Mahbub Rashid, Ph.D., RA \\ Professor \\ School of Architecture, Design and Planning \\ University of Kansas \\ 1465 Jayhawk Boulevard \\ Lawrence, KS 66045 \\ P: 785.864.4405 \\ F: 785.864.5185 \\ mrashid@ku.edu
}




\section{THE QUESTION OF KNOWLEDGE IN EVIDENCE-BASED DESIGN FOR HEALTH CARE FACILITIES: LIMITATIONS AND SUGGESTIONS}

\section{Introduction}

During the last decade or so, the evidence-based design (EBD) approach has made significant impacts on the healthcare design industry. Many different programs and publications including the Evidence-based Design Accreditation and Certification (EDAC) of the Center for Health Design (CHD), the Health Environments Research and Design (HERD) journal, the Healthcare Design (HCD) conference and journal, and the Environment Design Research Association (EDRA) conference provide ample evidence supporting the successes of the EBD approach for healthcare facilities. While the successes of EBD are numerous, notable limitations persist concerning how the proponents of EBD have defined 'what is' and 'what is not' the appropriate kind of knowledge for them to create, promote, adopt, and/or use. In this paper some of these limitations are discussed; and some suggestions are made to help overcome these limitations.

It is important to note here that this paper distances itself from some of the more frequent criticisms of EBD for healthcare facilities highlighting the distinctions between evidence-based medicine (EBM) and EBD, research and practice, and/or science and design [see Stankos \& Schwarz (2007) for a detailed exposition on these issues]. While these criticisms of EBD are important, this paper supports the notion that the problems of the EBD approach for healthcare facilities arise not from the fact that its proponents do not understand the above-mentioned distinctions. Rather, any emerging domain that wishes to use research-based evidence to inform practice must face these criticisms because the gap between research and practice in most fields 
remains great. EBM itself continues to face these criticisms (see, for example, Anderson, 2012;

Liberati \& Vineis, 2004; Sitaras, 2012; Saarni \& Gylling, 2004; and Tonelli, 2001). There is no doubt that with persistent collective efforts EBD will eventually bridge the gap between research and practice, just like the way EBM has done to become a major force in medical practice. Therefore, [THIS PAPER FOCUSES MORE ON BRIDGING THE GAP BETWEEN DESIGN RESEARCH AND PRACTICE AS IT DISCUSSES KNOWLEDGE CATEGORIZATION AND ACQUISITION IN RELATION TO EBD] this paper focuses more on bridging the gap between design research and practice as it discusses knowledge categorization and acquisition in relation to EBD.

\section{EBD and its limitations concerning knowledge categorization and acquisition}

According to $\mathrm{CHD}, \mathrm{EBD}$ is "the process of basing decisions about the built environment on credible research to achieve the best possible outcomes" (The Center for Health Design, 2012). The process, as defined by CHD, includes the following eight steps: 1) define evidence-based goals and objectives; 2) find sources for relevant evidence; 3) critically interpret relevant evidence; 4) create and innovate evidence-based design concepts; 5) develop a hypothesis; 6) collect baseline performance measures; 7) monitor implementation of design and construction; and 8) measure post-occupancy performance results. With regards to this definition, the scope of this paper is limited to the first three steps of the process that deal with "relevant evidence". Elsewhere, Kirk Hamilton, an early advocate of EBD, uses "best evidence" in place of "relevant evidence" (Hamilton, 2003, 2004). With Stichler, he writes, "Evidence-based design is a process for the conscientious, explicit, and judicious use of current best evidence from research and 
practice in making critical decisions, together with an informed client, about the design of each individual and unique project" [Italic added] (Stichler \& Hamilton, 2008, p.3).

As understood by the proponents of EBD, the relevant or best evidence needs to be created by "credible research," or by systematic review and/or meta-analysis of already reported research findings. Anjali (2006a, 2006b, and 2007), Cama (2009), Malkin (2008), McCullough (2009), Rashid and Zimring (2008), and Ulrich, et al. $(2004,2008)$ are some of the examples of systematic reviews of credible research and of frameworks to apply these credible research to EBD for healthcare facilities. These and other [EBD REVIEW ARTICLES AND PUBLICATIONS MAKE IT QUITE CLEAR THAT TAKING CUES FROM EVIDENCE BASED MEDICINE (EBM) THE PROPONENTS OF EBD FAVOR MAINLY EMPIRICAL KNOWLEDGE OF THE EXPERIMENTAL KIND IN HEALTHCARE DESIGN] EBD review articles and publications make it quite clear that, taking cues from evidence based medicine (EBM), the proponents of EBD favor mainly empirical knowledge of the experimental kind in healthcare design; and ignore the fact a large body of design-relevant knowledge may not fit very well in this category for a host of reasons [see below]. So far, the proponents of EBD for healthcare facilities have made no systematic efforts to gather and publish these other categories of empirical knowledge for their benefits. Therefore, the knowledge domains of EBD for healthcare facilities have remained narrow, rigid, and exclusionary. Though this position with regards to knowledge has served the purposes of EBD for healthcare facilities well during its early phases of development, if held tight by its proponents this position may soon stifle healthcare design research and practice for a lack of flexibility and inclusivity.

Concerning empirical knowledge, another limitation of EBD for healthcare facilities is the fact that its proponents favor design-relevant knowledge developed in domains related to healthcare 
only, such as healthcare design (most often limited to architecture, interior design, and environmental systems), medical sciences, healthcare economics, healthcare management, healthcare policy and law, and healthcare practice. As a result, EBD proponents have no mechanisms in place to gather design-relevant knowledge that already exists or that is currently being developed in many other fields of natural and social sciences pertaining to human health and wellbeing. Most important among these fields may be anthropology, biology, economics, engineering, geography, history, psychology, and sociology. Also interesting in this regard is the fact that the EBD proponents have made very little systematic efforts to collect knowledge from many design fields including game design, graphic design, industrial design, interaction design, product design, process design, instructional design, service design, visual communication, and web design.

Concerning empirical knowledge, further limitations of EBD also include the fact that its proponents encourage 'quantitative' research more than 'qualitative' research ignoring the fact that qualitative research has been an important mode of knowledge generation for centuries. While it is true that the methodologies for qualitative research has been formalized only during the past few decades (e.g., Creswell, 1998), seminal studies in many disciplines including anthropology [e.g., Levi-Strauss's The Savage Mind (1966), where he draws a distinction between the 'Bricoleur' and the 'Engineer'], history [e.g., Braudel's The Structures of Everyday Life(1981)], and sociology [e.g., Durkheim's The Division of Labor in Society(1997; original in French, 1893), where he draws a distinction between mechanical and organic solidarity] already indicate that qualitative studies can be at least as valuable as, and sometimes even more valuable than, quantitative studies for generating knowledge of human society and culture. Thus, it is no wonder that many valuable and pertinent concepts concerning how individuals, groups, and 
organizations may work in natural settings come from qualitative research. In the absence of any systematic efforts to organize the knowledge generated by qualitative research, the benefits of this knowledge for EBD also remain unknown.

What is more worrying is the fact that [THE EFFECTS OF THE LIMITATIONS OF EBD FOR HEALTHCARE FACILITIES CONCERNING KNOWLEDGE ACQUISITION AND CATEGORIZATION DO NOT REMAIN LIMITED WITHIN THE FIRST THREE OF THE EIGHT STEPS OF THE EBD PROCESS. THEY OFTEN TRICKLE DOWN TO IMPACT OTHER SUBSEQUENT STEPS OF THE PROCESS] the effects of the limitations of EBD for healthcare facilities concerning knowledge acquisition and categorization do not remain limited within the first three of the eight steps of the EBD process. These effects often trickle down to impact other subsequent steps of the process. Some of the impacts are more clearly manifest in many healthcare facilities design guidelines that codify and/or translate the available knowledge, including the "credible research" evidence, for design practitioners. For example, of all the 121 references of a 2012 guidelines for intensive care unit design (Thompson, Hamilton, Cadenhead, et al., 2012), about $38 \%$ are quantitative studies that use some form of experimental, quasiexperimental, and/or causal-comparative research design; about $22 \%$ are studies or reviews by those who promote EBD of healthcare facilities; and a significant part of the remaining references include other guidelines and building codes, opinion pieces published by the experts in the field, or simply publications that present the normative knowledge of the field. Not to mention, very little of the knowledge presented in the 2012 ICU guidelines is from any sources outside healthcare.

Healthcare design evaluations and pre- and post-occupancy performance assessments are among the other areas where the limitations of EBD for healthcare facilities concerning knowledge 
acquisition and categorization also have an indelible impact. Many of the best-practice examples presented in the Healthcare Design Journal of CHD and other EBD for healthcare design related publications (e.g., Cama, 2009; Malkin, 2008; McCullough, 2009) have frequently used the same metrics, methods and outcomes that were promoted in the research literature of EBD for healthcare facilities. The same is true for the Pebble Project and the Ripple Database of CHD. "Pebble Partners," mentions the CHD website, "work together to identify built environment designs and solutions that measurably improve patient and worker safety, clinical outcomes, environmental performance and operating efficiency" [Italics added] (www.healthdesign.org). Likewise, the CHD website mentions that one of the purposes for the Ripple Database is "[to] create a repository containing... best practice design strategies that were targeted to achieve desired outcomes in Patient Safety, Worker/Workplace Safety and Environmental Safety" (ripple.healthdesign.org). Among the measurable desired outcomes that all three of these mechanisms of CHD aim to improve through planning and implementing EBD include: increased patient, staff and family satisfaction; fewer healthcare associated infections; reduce staff injuries; improved workflow and process; reduced noise; fewer medication errors; return on investment for design innovations; reduced patient falls; reduced workplace turnovers; and improved response time (www.healthdesign.org). While these outcomes are important, it is the notice on the opening page of Ripple that grabs our attention:

NOTICE: Design, cultural, operational, and technological strategies found on this site have been used in some situations. Because there are always unique factors at work for every facility there can be no guarantee that any given strategy will produce the same results in other situations. These strategies will need to be further investigated to help us fully understand their impact. [Italics added] (http://ripple.healthdesign.org/about) 
This disclaimer or notice is a bit surprising given the fact that EBD is the process to help make strategic design choices based on credible research to achieve best possible outcomes (see above). In this disclaimer, the EBD proponents have unintentionally recognized the gap that exists between the knowledge required to make design choices and the knowledge they have defined as 'relevant evidence' for good healthcare facilities design. Yet, to this day no efforts have been made to overcome the existing limitations of EBD concerning knowledge acquisition and categorization in order to bridge the gap.

\section{How can EBD overcome its limitations?}

While the limitations of EBD concerning its knowledge base are quite clear, it is not clear how it can become more flexible and inclusive. In this regard, knowledge classification is an important issue. Every domain decomposes itself into classes, and then further decomposes these classes into sub-classes and elements at lower levels, generally in a hierarchical structure, to manage its knowledge base. Ideally, it is expected that the members of a class would share a number of characteristics significantly different from those shared by the members of another class. Although it may seem obvious that the question of shared characteristics among different classes or subclasses of a knowledge domain will be resolved according to the criteria set by the collective body representing the domain, in the absence of any guiding conceptual framework the knowledge classification of any domain may become arbitrary, imposed, and politically charged.

In fact, many would argue that EBD for healthcare facilities is in such an arbitrary, imposed, and politically-charged state in the absence of any guiding conceptual framework and a proper classification system for its knowledge base [see American Society for Healthcare Engineering 
[ASHE] 2008; Looker, 2008; and Stankos \& Schwarz, 2007]. As a new knowledge domain the lack of a guiding conceptual framework and a proper knowledge classification system of EBD may not be unusual and worrisome. The literature is replete with considerable philosophical debate as to whether all classifications are arbitrary and imposed, or whether they represent natural, real structures which can be 'correctly' recovered through empirical observation. Yet, the present state of EBD is a bit disconcerting since a great deal of research has already shown that all classification systems, to certain extent, are socially produced by the purposes, power structures, ideas, and beliefs of the societies which create them. In general, a logical system of classification is able to fend off these social and political forces better than the one that lacks a logical rigor [See Ellen and Reason (1979) for a good discussion of these issues.]

Even though research into classification has been of fundamental interest in the social and natural sciences, no easy path to knowledge classification exists for any domain (Conklin, 1964; 1969). This may be particularly true for a research-based practice domain like EBD for healthcare facilities. While any proper classification system for this knowledge domain must remain the responsibility of the collective body representing the domain, in a democratic society individuals must have the right to question the validity of the system and/or to make suggestions for improving the system. Therefore, a few suggestions are made below for the proponents of EBD for healthcare facilities to consider as the domain continues to grow and become more relevant to the design research and practice.

Altogether, there are four suggestions made here. The first of these suggestions is meant to encourage the proponents of EBD to broaden their scope of empirical knowledge of the experimental kind directly related to design profession and practice. Since aesthetic 
considerations are important for all design professions, the relevance of the experimental studies in the psychology and neuroscience of aesthetics to the EBD process are discussed here.

The second suggestion is meant to encourage the proponents of EBD to broaden their disciplinary scope of empirical knowledge. It is suggested here that the basic knowledge of design resides not only in aesthetic objects or what we do as design professionals, but also in everyday objects with little or no aesthetic value. It is also suggested here that the knowledge of human interaction with design is often embedded in the way humans organize societies and create cultural artifacts including symbolic systems. Donald Norman's book The Design of Everyday Things (2002) in psychology and Edward Hall's book The Hidden Dimension (1966) in anthropology are discussed here to illustrate the point that empirical knowledge of design can also be found in disciplinary areas that are not commonly associated with the production of aesthetic objects.

The third suggestion is meant to encourage the proponents of EBD to broaden their scope with regards to knowledge in general. It is argued here that design depends on different types of knowledge. Of which, empirical knowledge is only one kind. In this regard, the importance of logical knowledge, systemic knowledge, and semantic knowledge is emphasized in relation to design.

The fourth and final suggestion is meant to encourage the proponents of EBD to become more inclusive with regards to their research design approaches. Here, the limitations of experimental research design are discussed: first, in relation to its inability to provide 'absolute' knowledge; and, then, in relation to its inability to provide a 'rich and thick' description of the setting required for the purposes of design. In this regard, the values of qualitative research design are 
highlighted without indicating preference for any one qualitative research method over the others.

Suggestion 1: Broaden the scope of empirical knowledge of design of the experimental kind.

Design, as it refers to a generative process, is at the core of every discipline. Design as a collaborative activity often involves many different disciplines. Design, as it refers to all artificial artifacts, pervades our everyday life. Examples of design include buildings, cars, clothing, furniture, jewelry, medical instruments, paintings, sculpture, and many more things. Aesthetics, reliability and safety, usability, cost, comfort, spirituality, sustainability, and social equity and justice are only some of the functions a design may serve. It is often said that a great design of aesthetic value always strikes an appropriate balance and harmony among all its functions - no matter how extensive the list of functions may be. This is no different for the design of healthcare facilities.

The design of healthcare facilities provides figural/formal/spatial solutions to the functional requirements and problems identified in a design brief or program. These functional requirements and problems are rarely limited to those aspects identified so far as the important outcomes by the proponents of EBD for healthcare facilities (see above). A healthcare facility that produces the desired outcomes related to health, safety, and economy of the Ripple Database may not pass the test of a good architecture measured in terms of aesthetics, sustainability, and social equity and justice. Conversely, a healthcare facility that is considered a good architecture in terms of aesthetics, sustainability, and social equity and justice may not produce the desired outcomes of the Ripple Database. Therefore, the design of healthcare facilities needs to achieve 
both. On the one hand, it must help improve outcomes related to health, safety, and economy. On the other hand, it must also help improve the value of healthcare facilities in terms of aesthetics, sustainability, and social equity and justice.

In the recent days, great strides have been made in promoting social equity and justice through universal design. The Center for Universal Design at North Carolina State (http://www.ncsu.edu/project/designprojects/udi/) is a great source for research and resource materials related to universal design. Similarly, great strides have also been made in promoting sustainable design by such organizations as the United States Green Building Council (USGBC) and its Leadership in Energy and Environmental Design (LEED) certification programs (www.usgbc.org). In general, architects, including those working on healthcare projects, recognize the importance of universal and sustainable design. Integration between universal and sustainable design with EBD occurs in most healthcare facilities at the project level but a more inclusive framework is still needed. It must be a role of the proponents of EBD for healthcare facilities to create better and more structured interfaces among these various domains of design knowledge for their own benefits.

In contrast to the significant developments made in relation to architectural design for social equity and justice and sustainability in the recent days, a lack of interest can be observed with regards to any scientific knowledge of aesthetics among all groups of designers interested in a performance-based architecture including those promoting EBD for healthcare facilities. This is despite the fact that the importance of aesthetics in architecture has been fairly consistent in the history of human civilizations. Since Vitruvius - a Roman who wrote the first treatise of architecture, De Architectura, known today as The Ten Books on Architecture in the first century 
B.C. - a strong preference for the codification of aesthetic criteria in mathematical terms can be found in architecture.

Today, disinterest among architects concerning the science of aesthetics is a bit odd since it can be argued that the interest in the aesthetic values of architecture amongst architects have grown significantly more than ever before. With the increase in the complexity of building projects, the competitions for architects from other professions and occupations with overlapping expertise have increased significantly. Engineers, interior design, facility managers, developers, contractors, material suppliers, and product vendors are just a few among these professions. Already in the 1970s and 1980s, scholars have observed that architects have focused on the aesthetics of architecture more frequently than any other strategies in response to the challenges from the other building-related professions (e.g., McCue et al., 1970; Larson, 1974; Gutman, 1988). This is because aesthetics is an area where architects have claimed a special competence historically, and in which there is relatively little competition from other professions related to the building industry.

In light of the historical and professional significance of aesthetics in architecture, it may seem essential to integrate the science of aesthetics with EBD for healthcare facilities. A science of aesthetics is also interesting for the aesthetics of architecture is not limited to the notion of architecture as art. In architecture, researching and integrating aesthetic aspects of buildings are natural components of the work. Additionally, a science of aesthetics may also help limit the disparities that exist in aesthetic perception and evaluation between the architect and the user of the building. This is important because, it is often the case that an architect intentionally incorporates semantic aspects in the process of design to make buildings convey meaning but the user, who will use and experience the building, is not included in this process. Further, it can be 
argued that a science of aesthetics in architecture may be able to bridge the gap between the science and the art of architecture more effectively than any other building sciences.

The ultimate goal of a science of aesthetics is to help explain aesthetic processes - aesthetic appreciation, judgment, and production - based on a whole network of factors related to stimulus, personality and situation (Jacobsen, 2006). While a unified science of the aesthetics of architecture presents a huge challenge, the psychology and neuroscience of aesthetics already report significant progresses in relation to aesthetic processes. For example, there is already a considerable amount of empirical evidence directly relevant to architectural design review, which falls in the category of aesthetic judgment pertaining to architecture. Stamps (2000) reported that the literature contained about 275 relevant studies, covering 12,000 stimuli and more than 41,000 respondents. They included topics ranging from how strongly preference was influenced by articulating the façade of a single house to how much consensus there was over demographic groups with 19,000 people in 21 different countries.

The psychological studies reported by Stamps (2000) involved such architectural design concepts as shape complexity, whole, parts and details, visual richness, bulk, massing, façade articulation, character, and the visual commons. For architectural forms, Stamps (2000) reported, the current findings suggest that the impression of complexity can be predicted quite well $(\mathrm{r}=$ .78) from the number of turns in the outline of the form. In addition, the impression of complexity can be reduced about $25 \%$ if the form is symmetric. In contrast, Stamps (2000) reported, the empirical work on architectural detail is sparse but tends to support the hypothesis that detail is an important part of preferences for buildings. For architectural mass, Stamps (1998) found that the most influential variable was visual area $(r=.97)$. These are just a few 
among many findings reported by Stamps (2000) that appear to be relevant to EBD for healthcare facilities.

For EBD proponents, it is important to note that one common criticism against the relevance any psychological study of aesthetic judgment to architectural design review is that the study applies to a feeling by one person, at one time, about one thing or event. In contrast, design review necessarily presupposes a prediction of the feelings of many people over the life of a project. Therefore, any useful theory of the aesthetics of the built environment for EBD must include connections between the feelings of individuals included in the study and that of many other people. Meta-analysis is a statistical technique that allows us to draw such connections by combining the findings of more than one experiment into a collective estimate [see Stamps (2000) for more on meta-analysis]. Using meta-analysis, Stamps (2000) studied the reliability and generalizability of the scientific studies on the aesthetics of the built environment reported in his book. In one meta-analysis that included the empirical literature on demographic effects in environmental aesthetics, he found that consensus tended to be quite high $(\mathrm{r}=.83$ to $\mathrm{r}=.89)$ over most demographic differences. "Overall," wrote Stamps, "the available evidence suggests that demographic effects of environmental preferences are not nearly as strong as the conventional wisdom would suggest" (Stamps, 2000:134). Based on other similar findings using meta-analysis and, in some cases, factor analysis of the available data covering a wide range of people and places, Stamps concluded that the public interest in environmental aesthetics has been very well defined in the literature.

Despite Stamps' above conclusion, the proponents of EBD must be careful concerning many empirical findings on environmental aesthetics reported in the literature. In many cases, questions concerning these findings are the same as they were in the past. The conflict between 
the degree of experimental control on the one hand and the range of generalizability of the findings is still an issue. In the case of psychological studies of aesthetics simple geometric shapes and lines are attractive stimuli for the scientist, because controlled variations are possible. But, the question is, can individuals produce genuine aesthetic judgment about such simple object, or can aesthetic judgments about these simple objects be used to explain and understand the aesthetic judgment of architecture? Most aesthetic objects including architecture combine variations of several stimuli that cannot be sufficiently replicated in an experimental setting. As a result, it is not always easy to come to a conclusion about aesthetic processes based on psychological studies.

Besides the psychology of aesthetics, empirical aesthetics or experimental aesthetics is also found in the neuroscience of aesthetics (or, simply neuroaesthetics). More than one and a half centuries ago, in The Elements of Psychophysics Fechner distinguished between an outer psychophysics for the study of the relationship between human psychology and the physical properties of the stimuli, and an inner psychophysics for the study of the relationship between human psychology and the physical properties of the brain (Fechner, 1860). Today, Fechner's inner psychophysics, which includes neuroaesthetics, is pursued by neuroscience using such tools as functional magnetic resonance (fMRI), magnetoencephalography (MEG), electroencephalography (EEG), and event-related potential techniques (ERPs) [for an introduction to neuroaesthetics see Shimamura and Palmer, 2012].

Chatterjee $(2010,2012)$ put the literature of neuroaesthetics in three categories - those that describe the parallel organizational principles of the brain and the intent and the practice of artists, those that describe anecdotes relating aesthetic experience and the brain, and those that present experimental neuroaesthetics. Zeki (1999a, 1999b) and Ramachandran and Hirstein 
(1999) exemplify the parallelism approach by suggesting that the goals of the nervous system and of artists are similar. Artists decomposes, isolates, and enhances different visual attributes of objects or environments just like the way nervous systems decomposes visual information into such attributes as color, shape, luminance, and motion. What is more interesting is the fact that, as some of these researchers argue, visual modules, processes, and distinctions discovered by artists are often those that are functionally and anatomically distinct within the brain. Richard Latto's (1995) discussion of the use of irradiation in George Seurat's Bathers at Asnières, Margaret Livingstone's $(2000,2002)$ discussion of the elusive smile of Leonardo's Mona Lisa, and Lizann Bonnar, Frédéric Gosselin, Phillipe Schyns (2002) discussion of Salvador Dali's Disappearing portrait of Voltaire provide some examples of the concept of parallelism being applied in painting.

Diseases of the brain and brain injuries can impair our ability to speak or comprehend language, to coordinate movements, to recognize objects, to apprehend emotions, and to make logical decisions. Paradoxically, in some cases diseases and injuries seem to improve our artistic ability; thus giving us a way to understand how our brain functions aesthetically. Chatterjee $(2010,2012)$ classifies this type of knowledge as the anecdotal knowledge of neuroaesthetics. In one of these cases, a German artist, who suffered a right hemisphere stroke in 1911, often left out the details of the left side of his paintings; thus creating a style that shifted him into the circle of great artists (Alfred Kuhn, quoted in Gardner, 1975).

Experimental neuroaesthetics, in contrast to parallelism and anecdotes, focuses on aesthetic experience as a combination of responses in various components of the brain in relation to stimuli. Studies show that the nervous system processes visual information in hierarchical sequence and in parallel. Early vision extracts simple elements from the visual environment, 
such as color, luminance, shape, motion, and location. These simple elements are processed in different parts of the brain. Intermediate vision segregates some elements and groups others together to form coherent regions. Late vision selects which of these coherent regions to scrutinize and evokes memories from which objects are recognized and meanings attached (Farah, 2000). Likewise, scientists observe that form of any artwork is processed by early and intermediate vision, whereas content is processes by later vision. Thus, the early vision features of an art object might be its color and its spatial location. These elements would be grouped together to form larger units in intermediate vision (Ishai, Fairhall, \& Pepperell, 2007).

In addition to the perception of art objects, neuroaesthetics also helps inform aesthetic judgment and emotional response. For example, studies show that some universal components of art have distinct neural underpinnings as opposed to others which are shaped by culture (Cunningham, Barbee, \& Philhower, 2002). Studies also show that some areas of the brain respond to beauty automatically, and that emotional responses to attractiveness may be distributed among different areas of the brain (Chatterjee, Thomas, Smith, \& Aguirre, 2009).

In general, experimental studies of aesthetic processes in neuroscience can be conducted in two different ways (Chatterjee, 2010; 2012). In one way, neuroscientists use properties of objects, possibly aesthetic objects, to probe the properties of brain. The goal of these experiments is to understand how finely characterize stimuli are related to the spatial and temporal response properties of neurons. In another way, neuroscientists use the brain to probe the psychology of aesthetics to answer such questions as this: "Do certain areas of the brain simply serve classification functions distinguishing some stimuli for others, or do they also serve an evaluation function distinguishing some stimuli more appealing than others?" (Chatterjee, 2010) Regarding the latter Chatterjee notes, "one-to-one correspondences between neural activation 
and psychological processes may be rare in the brain. Findings of localized activations to specific stimuli more often generate hypotheses about the mental processes involved, rather than confirm these hypotheses" (Chatterjee, 2010: 59). Therefore, neuroaesthetics will still need to work in conjunction with the psychology of aesthetics in order to explain aesthetic processes. Neuroaesthetics also has some of the same problems of the psychology of aesthetics with regards to experimental control (see above). Additionally, the studies in neuroaesthetics have been sparsely distributed over several areas. As a result, it does not yet provide enough knowledge to have any significant impact in any one area of aesthetic studies. However, the most limiting factor of neuroaesthetics with regards to architecture is the fact that it reports no study involving architecture.

Yet, recognizing the importance of neuroscience in relation aesthetic processes in particular and cognition in general, in his book Brain Landscape, Eberhard asks neuroscientists to help architects answer why certain environments elicit predictable behavioral or psychological responses (Eberhard, 2009). On the basis of the findings reported in the environmental psychology and behavior literature, Eberhard proposes 34 hypotheses for neuroscientists to test experimentally for neuroscientific explanations. In a way, Eberhard challenges neuroscientists to find one-to-one mapping between neural processes and psychological processes, which, according to Chatterjee, is rare (see above). Therefore, the proponents of EBD will need to find other better ways to integrate the neuroscience and the psychology of aesthetics with their own program of design research and practice. At the same time, the EBD proponents will also need to consider the fact that aesthetics is only one of many important aspects of design. To help understand some of these other non-aesthetic aspects of design, they will have to look beyond the traditional domains of design. 
Suggestion 2: Acknowledge the fact that design involves many disciplines in human and natural sciences.

No matter how complex and diverse design processes and designed objects are, human issues are always among the most important issues to consider in design (i.e., man-made artifacts). Though human-design interaction is generally governed by human physiology, psychology, history, society, and culture, the good news for designers and design researchers is that most basic human traits are relatively stable and they change only very slowly. Therefore, we do not need to design for every individual needs. Rather, we design for humans in their context, with the hope that if all fundamental human issues involving design are taken into account with reasonable care then it is possible to satisfy individual needs sufficiently.

Over the years, scholars and researchers in numerous disciplines have identified many principles explaining the fundamental relationships between design and human physiology, psychology, history, society, and culture. Since an exhaustive survey of this literature is beyond the scope of this paper, Donald Norman's book The Design of Everyday Things (2002) in psychology and Edward Hall's book The Hidden Dimension (1966) in anthropology are discussed below to indicate the relevance of this literature to EBD for healthcare facilities, even though this literature is not directly related to healthcare design or to the production of aesthetic objects.

Donald Norman, in his The Design of Everyday Things (2002) [published originally as The Psychology of Everyday Things in 1988], provides several psychological principles pertaining to the design of everyday things ranging from doorknobs to telephones to bathroom fixtures to nuclear power plants to air traffic control rooms. He offers these principles as tools for designers 
to ensure that their products, whatever may that be, are useable and understandable. One example of Norman's design principles is that every good design is an act of communication between the designer and the user as defined by the interface and appearance of the device. The device must explain itself based on simple conceptual models. A device fails when users are not able to understand the conceptual model provided by the device. Another example of his design principle is that the surest way to prevent making a mistake when using a device is to limit the use of the device in any other harmful way. Yet another example is that every design must give a user some feedback regarding whether a goal of his action involving the design has been achieved or not. Otherwise, the user is concerned about the designed object (i.e., device) or about her abilities_ — “is the device working?" or, "am I doing something wrong?" In the absence of feedback, the user may even become disinterested - "if it does not work, why do I care?" or "if it does not work, why do I need to invest resources on design?" Norman did not study healthcare design to develop his principles, but the relevance of these principles to the EBD approach for healthcare facilities is clear.

Concerning EBD for healthcare facilities, the most important principle given by Norman is probably that every design must afford users to act on it purposefully. For example, a chair must allow sitting, thus providing a natural mapping between its affordance and purpose. Norman uses the term "perceived affordability" to describe the degree to which the affordance of an object maps onto its purpose (Norman, 1999; 2002). If a chair does not allow the perceived affordance of 'sit-ability', then the natural mapping between its purpose and affordance does not exist. Since this absence of natural mapping breeds problems, one of the many goals of design research has been to understand how "perceived affordability" work in relation to design and its end users (e.g., Hartson, 2003; Kannengiesser and Gero, 2012; Maier and Fadel, 2009a, 2009b). 
Norman's "Perceived affordability" or "perceived affordance" is not something isolated in psychology and cognitive science. It is one of many prescriptive formulations of a more generic concept of affordance first introduced by the perceptual psychologist James Gibson $(1977,1979)$ as a part of his proposal for an ecological perception:

The affordances of the environment are what it offers the animal, what it provides or furnishes, either for good or ill. The verb to afford is found in the dictionary, but the noun affordance is not. I have made it up. I mean by it something that refers to both the environment and the animal in a way that no existing term does. It implies the complementarity of the animal and the environment. (Gibson 1979, p. 127; emphasis is the author's)

Gibson (1979) argued that it is through the perception of affordances that animals perceive their environment, and that in any interaction between an animal and its environment, inherent conditions or qualities of the environment (i.e., affordances) allow the animal to perform certain actions with the environment. In general, positive affordances encourage human interactions, and negative affordances discourage them.

Since Gibson (1979), the concept of affordance has been the subject of much study and application within perceptual psychology. More recent examples of these studies include those reported by Bingham (2000), Gibson (2000a, 2000b), Lintern (2000), Pickering (2000), and Stoffregen (2000). It is precisely because of this body of experimental evidence and application in practice, the concept of affordance is an established psychological theory ready to be applied to design. 
Therefore, it is not surprising that the concept of affordance has been used by many in different fields of design research. For example, inspired by the work of Norman on "perceived affordability", researchers in the industrial design community have already adopted the concept of affordance to study the symbolic qualities of manufactured forms in the cognitive and social contexts of their use and application. A concise review of the use of affordance in this field is given by You and Chen (2007). Some researchers in computer engineering have also used an affordance based approach to design usable and intuitive physical interfaces for computing devices (Sheridan and Kortuem, 2006). The idea of affordance has also been applied in the field of artificial intelligence, e.g., how to design robots that recognize affordances in their environment (Murphy, 1999). The application of the theory of affordances to architectural design has also been advocated in a recent paper (Maier, Fadel, \& Battisto, 2009).

Today, the theory of affordance and its many prescriptive formulations are often used for explaining 'situated cognition' - a view that all forms of knowledge are situated in their context, activity, people, culture, and language (e.g., Greeno, 1994; 1998). Opponents of situated cognition, however, argue that it is wrong to suggest that all forms of knowledge are bound to the specific situations in which they occur, and that whether knowledge is bound to its context or not depends on both the kind of knowledge and the way it is acquired. Similarly, proponents of a more category-based model of perception have long challenged Gibson's notion of ecological perception based on affordances. These conflicting viewpoints regarding affordance indicate that it may not always be easy to apply a psychological theory to design even when the theory appears important.

In contrast to the psychology of perception, Edward Hall, an anthropologist and cross-cultural researcher, focused his research on cultural perceptions of space, and emphasized the essential 
indeterminacy of culture in the context of design (Hall, 1959, 1966). He used such terms as proxemics, polychronic vs. monochronic, and high context vs. low context culture to describe peoples' perception of space in different cultures. Hall also categorized various environmental elements to help define human's relation to space anywhere, everywhere. His categories include infracultural elements of the environment that are rooted in human's biological past. Examples of these elements include crowding and territoriality. His categories also include precultural elements related to human physiology and senses. Hall further categorizes precultural elements in relation to distant receptors such as eyes, ears, and nose, and immediate receptors such skin and muscles. His next category is cultural elements that include art, literature, music, and language. Finally, he has microcultural elements, also known as the study of proxemics that describes the subjective dimensions that surround each of us and the physical distances one tries to keep from other people, according to subtle cultural rules. Hall's book The Hidden Dimension (1966) includes, among other things, the findings of his studies on the interplay of the distant and immediate receptors in proxemic perception. Because of their general importance for humans as users in and of the environment, Hall's findings must be relevant to EBD for healthcare facilities as well. Again, it is important to note that Hall did not conduct his studies in healthcare facilities.

Hall's categorization of the microcultural elements at the level of proxemics in terms of fixed feature, semi-fixed feature, and informal feature spaces (Hall, 1966) may also be important for EBD for healthcare facilities. Even though the definitions of these features can vary from one culture to another, within a culture they remain stable. According to Hall, the fixed-feature space generally comprise of things that are immobile, such as wall and territorial boundaries. In most cultures they also include the hidden internalized codes that govern behavior. Hall notes that the use the fixed feature space varies from one culture to another in time and space, and a proper 
cultural orientation in the fixed feature space is important for both survival and sanity. For example, in the USA we drive on the right hand side of the street, whereas in Europe they drive on the left-hand side. Therefore, we may put ourselves in danger if we do not learn this simple rule of driving that rests on the fixed feature space. Many other examples of the differences among cultures exist in the way buildings are built, roads are laid out, streets and floors are named and numbered, public spaces are used, or even in the way foods are prepared and served. Our language, literature, music, food, and many other cultural artifacts are a rich source for better cultural understanding of how we use our fixed feature spaces. It may be easy to access some of this knowledge, but someone needs to collect them, organize them, and update them for designers to use. These cultural cues are too important to be left aside in design or only to be occasionally used by the designer in an unconscious manner.

Hall's semi-fixed feature space is comprised of movable objects such as furniture. They do not occupy space permanently, but their effects on behavior are profound and measurable. Since observations made concerning semi-fixed features in one situation may not be applicable to another, we need empirical research to understand how a semi-fixed feature space is being used in a given context. Here too, a body of empirical knowledge is already available that may need no further validation for the design of healthcare facilities. That is because, as mentioned before, some elements of human psychology and behavior appear to remain stable in time and space until they are forced to change deontically (i.e., by rules and conventions). [For a list of studies on how people respond to fixed and semi-fixed features see Gifford, 2002; Bechtel and Churchman, 2002; and Bell, et al., 2005].

Finally, Hall's informal space is composed of several layer of space around one's body. This bubble moves with the person affecting how she maintains her physical distance from others. 
According to Hall, this bubble is comprised of intimate space (generally limited to a distance $<1.5$ feet from a person), personal space (generally limited to a distance $<4$ feet from a person), social space (generally limited to a distance $<12$ feet from a person) and public space (generally limited to a distance $>12$ feet but $<25$ feet from a person). Similar informal bubbles seem to exist for animals as well, comprising of flight distance, critical distance, personal distance, and social distance.

In summary, Hall's anthropological theory of space developed based on proxemics is important in relation to how we interact with the environment and with others in the environment. It can be applied to the design of healthcare facilities with some caution, because his positivist desire to measure and characterize the cultural spaces surrounding individual is only one of many anthropological theories of body, space, and culture. Many within anthropology would argue that Hall's spatial analyses neglect the body "as a physical and biological entity, lived experience, and a center of agency, a location for speaking and acting on the world" (Low, 2003). To overcome this limitation, some anthropologists have studied how our habits of the body generate cultural features and social structure (e.g., Bourdieu, 1984). Others have noted the importance of movement in the creation and conception of space (e.g., Pandya, 1990). Yet others have conceived the body as a moving spatial field capable of making its own place in the world (e.g., Munn, 1996). In simple words, several anthropological theories of space exist to inform our interaction with the environment. It depends on the proponents of EBD to decide how these theories ought to be categorized for their purpose.

[AS ONE READS THROUGH THE LITERATURE RELATED TO A RANGE OF NATURAL AND SOCIAL SCIENCE SUBJECTS INCLUDING ANTHROPOLOGY, BIOLOGY, ECONOMICS, ENGINEERING, GEOGRAPHY, HISTORY, MEDICINE, PSYCHOLOGY, 


\section{AND SOCIOLOGY, ONE FINDS THE EVIDENCE FOR GOOD DESIGN EVERYWHERE.]}

As one reads through the literature related to a range of natural and social science subjects including anthropology, biology, economics, engineering, geography, history, medicine, psychology, and sociology, one finds the evidence for good design everywhere. One wonders, what would it take to include some of these findings as relevant empirical knowledge for good design? For the EBD proponents, the answer is easy. They would probably like to see that all design-relevant knowledge created using appropriate scientific research methods eventually be integrated with the knowledge base of EBD for healthcare facilities regardless of the disciplines of origin of the knowledge. This is already evident in the recent attempts to integrate the findings of neuroscience research with architecture (e.g., Zeisel, 2005; Eberhard, 2009). These attempts are laudable since it is generally very hard to validate complex architectural experience through studies of the brain (see above). In this overemphasis on empirical knowledge of the experimental kind, the EBD proponents often forget that this is only one category of knowledge among the many different categories of knowledge required in the process of design. Therefore, we discuss some of these categories of knowledge and their relevance to design next.

Suggestion 3: Acknowledge the fact that design involves several types and qualities of knowledge.

Design is more than mere packaging of empirical knowledge in figural forms. The knowledge base of an expert designer, like most of us, is made up of different categories of knowledge including empirical knowledge. Depending on our interests in design, the knowledge of an expert designer can be put in many of the following categories: a priori and a posteriori 
knowledge, verbal (analytic) and pictorial (analog) knowledge, generic (or general) and domain specific (or situated) knowledge, concrete and abstract knowledge, formal and informal knowledge, conceptual and procedural knowledge, elaborated and compiled knowledge, unstructured and (highly) unstructured knowledge, deep and surface knowledge, automatic and non-automatic knowledge, tacit and explicit knowledge, and strategic and tactical knowledge [See de Jong and Fergusson-Hessler (1996) for the definitions of many of these knowledge types].

This list of knowledge categories is in no way exhaustive. Many of these categories may also significantly overlap with each other. Additionally, knowledge categories do not have to be always identified by the semantic opposites. Further, any one system of classification may include several of these knowledge types. For example, the literature on detailed task analysis identifies four types of knowledge in the system of knowledge classification (de Jong and Fergusson-Hessler, 1996). They are situational knowledge, conceptual knowledge, procedural knowledge, and strategic knowledge. For some, such a system of classification of knowledge may be too narrow for design because it downplays the role of figural and semantic knowledge. Therefore, it is important that EBD identify a system of knowledge classification for design from its perspective to better define the scope of its knowledge base.

To identify an appropriate method to categorize knowledge is not the only concern for EBD. For it, the methods of knowledge acquisition must have to be as important as the types of knowledge because its programs are based on the notion that for good design we need good empirical knowledge gained by scientific methods. In the next section, we discuss the limitations of this position by highlighting the differences between empirical knowledge gained by quantitative and qualitative methods. Here, we discuss the limitations of this position by highlighting some of the 
more fundamental categories of knowledge, which include logical knowledge, systemic knowledge, empirical knowledge, and semantic knowledge. Each of these categories involves different methods of acquisition. It clear why empirical knowledge is important for EBD, but it is not so clear why the other categories are not important for its purpose. Therefore, we discuss each of these other categories in an effort to establish the point that the knowledge base of EBD cannot be complete without taking into account all different categories of knowledge acquisition.

Logical knowledge is the result of the understanding of the relationship of ideas to one another. There are the rules or laws of logic that permit claims to knowledge. Many argue that logical knowledge may sometimes be fallacious concerning design that involves human matters. These critics of logical design knowledge forget the fact that the world of design often involves physical matters. Therefore, it may be perfectly fine, for examples, if one uses logical arguments concerning the physical form, materials and methods of buildings. In fact, many areas of design already use various techniques of logical argumentation to inform design and design processes [see Groat \& Wang (2002) for a good discussion on the topic]. One wonders, if this body of knowledge can someday become a part of the knowledge base of EBD.

Systemic knowledge of design includes the mathematical and geometrical principles of design. Generally, we expect that all designers should know at least the more important ones of these principles. Unfortunately, they do not know them and, as a result, make avoidable design mistakes. A well-known geometric principle is that 'a circle is the most compact shape for any given area' - a principle that may be relevant to walking distance and visibility in nursing units. Another well-known principle is that 'the perimeter-area ratio of a rectangular shape depends on its length-width ratio' - a principle that has obvious implications for those who want to maximize the number of patient rooms with outside view and natural light. 
In contrast, a less-known principle is demonstrated in Fresnel's diagram (Fig. 1). In the diagram, each successive annular ring diminishes in width but has exactly the same area as its predecessor. Put simply, the outer band in the square form of this diagram has exactly the same area as the central square. This is an important principle in relation to the way in which buildings may be placed on the land. Using theoretical studies done based on this principle, Martin (1972) show that for any given floor area it is possible to save more usable outdoor space if we place buildings with the same height around the periphery instead of placing them at the center of a piece of land. One would imagine that this simple principle might be of some use for those designing the next urban hospital. Unwin (1912) also used this same geometrical principle to make a neat point about commuting time: as the population increases round the perimeter of a town, the commuting time is not increased in direct proportion to this. One wonders if this line of thinking could be applied to reduce walking distance and time in a hospital.

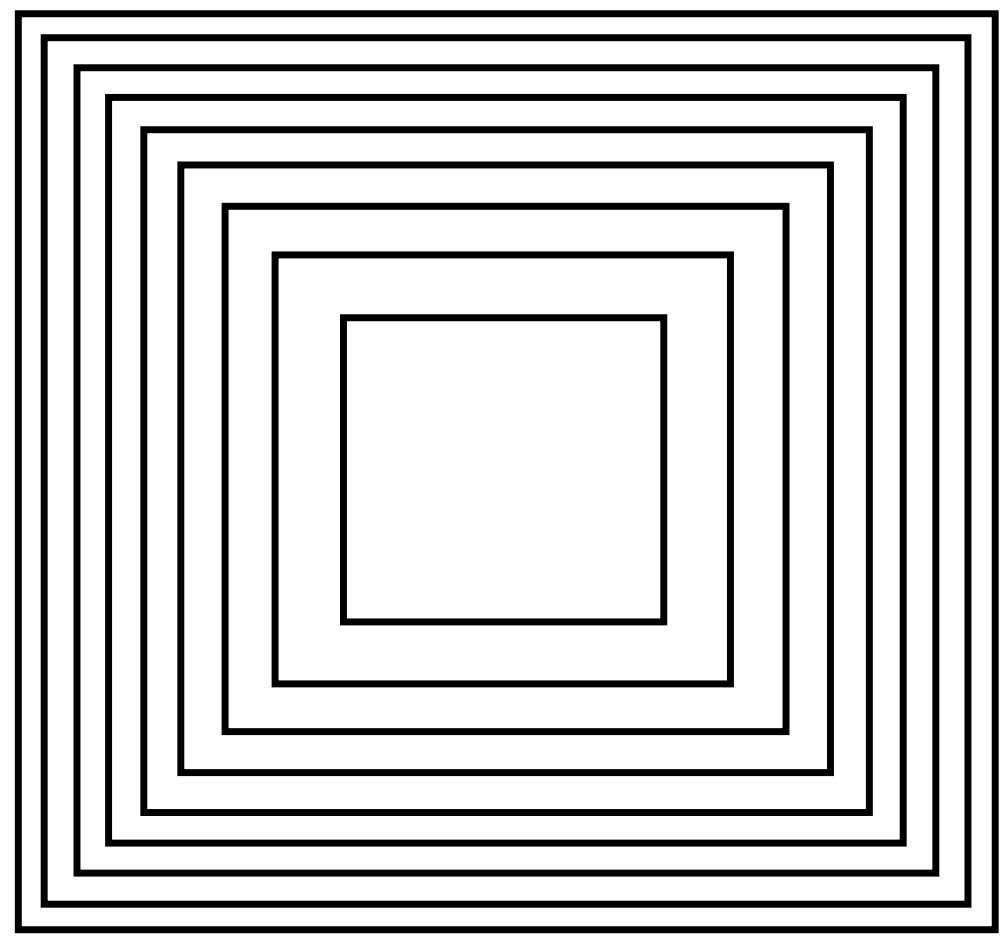

Figure 1: Fresnel's diagram 
Martin and March (1972) brought together a set of propositions about the geometry of built forms relevant to the efficiency of space use in corridor layouts, plot ratios of office developments, and the comparative land-use performances of different generic forms of buildings. Though comparable geometric propositions for healthcare facilities in particular are yet to be developed, interests in modeling hospital functions and the geometric attributes of design go back to the Nuffield Report in UK by the Nuffield Provincial Hospitals Trust and the University of Bristol (1956) and to the Yale studies in USA reported by Thompson and Goldin (1975). More studies of this kind are needed for a design practice domain like EBD, because a proper understanding of the basic mathematical and geometric principles of form and shape in relation to functions may help open up the range of choices and opportunities for flexibility, efficiency, and effectiveness in healthcare design.

Finally, semantic knowledge refers to the knowledge related to meanings, understandings, and other concept-based knowledge unrelated to specific experience. It is different from episodic knowledge, which refers to the knowledge of a specific event. For instance, people can answer questions like "Are houses buildings or boats?" without remembering any specific event in which they learned that houses are buildings. In contrast to logical and systemic knowledge, there is no one way to acquire semantic knowledge. The development of semantic knowledge continues throughout our entire lives beginning at the infant stage. Some of the many methods we use for acquiring semantic knowledge are reason and logic, mathematics, experiment, simulation, trial and error, observation, experience, intuition, and arguments from religious, literary, political, philosophical or scientific authorities. The obvious question is, "How do we take into account the semantic knowledge of design in EBD?" [CERTAINLY, EMPIRICAL KNOWLEDGE GAINED BY EXPERIMENTAL METHODS IS NOT ENOUGH TO 
UNDERSTAND OUR SEMANTIC ASSOCIATION WITH DESIGN.] Certainly, empirical knowledge gained by experimental methods is not enough to understand our semantic association with design. On this matter, qualitative research may be helpful, to which we turn next.

Suggestion 4: Promote qualitative research to better understand our semantic association with design.

Put simply, EBD promotes a design practice based on reliable research. It supports original empirical research as well as episodic research within generative design activities in the form of analysis and evaluation of design, action research, and/or collaborative research. In order to achieve its goals, EBD adopts Cochran's view of EBM (1972) that promotes controlled research studies, more specifically randomized clinical trials (RCTs), as the most valuable source of knowledge supporting clinical practice (Hamilton \& Stichler, 2008). Undoubtedly, experimental research studies provide better ways to produce reliable empirical knowledge but in the context of healthcare facilities design how much better is this knowledge than the knowledge gained by a well-designed qualitative research study?

Even though the positivist tradition in natural sciences has long promoted experimental research as the primary mode of knowledge generation, we already know that rigorous experimental research does not produce absolute knowledge - a point first made by Thomas Kuhn in The structures of Scientific Revolution (1962). Briefly, according to Kuhn, the work of a natural scientist is often done in artificial bubbles of constructs, concepts, and/or worldviews called paradigms that are mere socio-political mechanisms promoting certain kinds of research as 
opposed to the other kinds. Therefore, the work of a scientist who follows the positivist tradition of experimental research is not insulated from societal forces, something that the scientific community did not like to believe before him. Later, Kuhn's position concerning the relativity of scientific knowledge was further ratified by Karl Popper (1963). According to Popper, natural sciences often follow a hypothetico-deductive method, where a hypothesis about an observed phenomenon is proposed now and validated later only to be refuted or falsified in future. That is because no empirical knowledge can ever be proven true with absolute certainty. Science is better when it has taken more attempts to refute or falsify any given knowledge. In the absence such attempts, science becomes pseudo-science.

Nowadays, scientists support Kuhn's view more openly than ever before in relation to the impact any scientific knowledge may have on the society. For example, in a conference on "The Science of Science Communication" organized by the National Academy of Sciences, Daniel Kahneman (2012) states that science is just another religion with its own rituals and claims. And like all other religions, it is false or it could be false - there is certainly no guarantee that it is true. Therefore, he argues that in order for any scientific evidence to have an impact the source of the evidence (i.e., the scientific establishment) must have to liked and trusted. We, as public, pay less attention to the knowledge put forward by the establishments we dislike.

Scientists also support Popper's view more openly nowadays. Whereas Popper thought a hypothesis is good for science to start with, today many people would argue that a hypothesisdriven science might not be good after all. That is because if you have too strong a hypothesis, you might become naturally invested in it. You would want to prove it. As result, you would miss all the important questions that you could ask. This is exactly the point Stuart Firestein makes in his book Ignorance: How It Drives Science (2012). Instead of hypothesis being the 
propeller of science, says Firestein in an NPR interview, science should be propelled by "what we don't know, what we need to know, what we'd like to know, what we think we could know, what we may not even know we don't know just yet and things of that nature" (Firestein, 2012). The point being made here is that if science exists to find an answer to a question, then science may as well be dead. Sadly enough, this is exactly what we are asking environmental researchers to do when we ask for more evidence supporting a design hypothesis. Should we not rather ask them to find us a few more problems to solve to make design better?

The point Kuhn, Popper, and many other people after them have made over the years can be summed up for our purpose here in the following manner: the empirical knowledge put forth by experimental research is not above and beyond skepticism. Therefore, we may as well take more interests in qualitative research for the benefit of the EBD approach for healthcare facilities. This is because experimental research is not only difficult to conduct but is also too narrowly focused for environmental studies in healthcare facilities. It is not surprising that after more than a decade of its inception controlled experimental studies involving the interaction effects of environmental, demographic, professional and organizational variables on an outcome variable are still rare in the literature related to EBD. For example, we do not yet know, with any degree of certainty, how the effects of noise on a female nurse in charge of three patients in an artificially-lit open-model intensive care unit (ICU) may vary from that of a male nurse in charge of the same number of patients in a closed-model ICU with natural light. Certainly, it is possible to design a study to look into the matter, but is it worth taking the trouble?

One thing to remember here is that for design we need qualitative knowledge that tells the story of how messy individuals, groups, and organizations are in any given environmental setting, so that we can try to make things better by design. For this, an empirical study using qualitative 
research methods may be more appropriate than an experimental research study. [OUR

FIGURAL AND SEMANTIC KNOWLEDGE, AS OPPOSED TO THE PROCEDURAL KNOWLEDGE, OF DESIGN DEPEND MORE ON REDUNDANT INFORMATION BASED ‘THICK AND RICH’ FIRST-HAND DESCRIPTIONS OF A DESIGN SETTING THAT NO AMOUNT OF EMPIRICAL KNOWLEDGE GAINED BY EXPERIMENTAL RESEARCH

MAY PROVIDE.] Our figural and semantic knowledge, as opposed to the procedural knowledge, of design depend more on redundant information based 'thick and rich' first-hand descriptions of a design setting that no amount of empirical knowledge gained by experimental research may provide. If the validity of empirical knowledge is important for EBD, then the researcher can easily achieve that goal in qualitative studies by taking any one or all of the following measures: spend a prolong time in the field; triangulate different data sources to build a coherent justification of the emerging themes; take parts of her polished analysis back to the participants to check accuracy; use peer debriefing to enhance the accuracy of her account; use rich, thick description to convey her findings; clarify her bias adequately; present negative or discrepant information that runs counter to her themes; and/or use an external auditor to review entire project as needed.

\section{Conclusion}

To conclude, it needs to be restated that EBD is rapidly evolving into a domain of study that healthcare providers and designers must use to improve healthcare design for better outcomes. Therefore, it is necessary that we study the foundations of knowledge of EBD with moderated skepticism while it is still in its developmental stages. If we fail to reassess its knowledge base 
now, it may be too late to make any changes to it in the future. To reassess the foundations of knowledge of EBD with moderated skepticism is necessary because there are philosophical and analytical problems yet to be overcome in delivering on the promises of EBD. This is necessary also because EBD offers tools and concepts concerning practical solutions to the challenge of a rational practice of design, which are superior to most of the available alternative approaches. To question and reassess the foundations of knowledge base of EBD is not necessarily to deny its value, but rather to stimulate a judicious and balanced appraisal of its limitations. So that, in future we are able to take necessary steps to overcome these limitations. This paper is presented in that spirit. 


\section{References}

American Society for Healthcare Engineering. (2008). Advisory and alerts: Considering evidence-based design? Retrieved on July 28, 2012, from

http://www.ashe.org/advocacy/advisories/2008/

Anderson, H. (2012). Mechanisms: what are they evidence for in evidence-based medicine? Journal of Evaluation in Clinical Practice, 18 (5), 992-999.

Bechtel, R. B., \& Churchman, A. (2002, Eds.), Handbook of environmental psychology, Wiley, New York, NY.

Bell, P. A., Greene, T., Fisher, J., \& Baum, A. S. (2005, Eds.), Environmental Psychology (5 $^{\text {th }}$ Edition), Lawrence Erlbaum Associates, New Jersey, NJ.

Bingham, G. P. (2000). Events (like objects) are things, can have affordance properties, and can be perceived. Ecol Psychol, 12(1), 29-36. doi:10.1207/S15326969ECO1201_2

Bonnar,L., Gosselin, F., \& Schyns, P. G. (2002). Understanding Dali’s Slave Market with Disappearing Bust of Voltaire: A case study in the scale information driving perception. Perception, 31, 683-691.

Bourdieu, P. (1984). Distinction. Cambridge, MA: Harvard University Press.

Braudel, F. (1981) Civilization and Capitalism: $15^{\text {th }}-18^{\text {th }}$ Century: Vol. 1. The Structures of Everyday Life. New York: Harper \& Row.

The Center for Health Design. (2012). Evidence-based design. Retrieved on July 28, 2012, from http://www.healthdesign.org/edac/about

Cama, R. (2009). Evidence-based Healthcare Design. New York: John Wiley \& Sons.

Chatterjee, A. (2010). Neuroaesthetics: A Coming of Age Story. Journal of Cognitive Neuroscience, 23(10), 53-62.

Chatterjee, A. (2012). Neuroaesthetics: growing pains of a new discipline. In Shimamura, A. P. \& Palmer, S. E., Eds., Aesthetic Science: Connecting Minds, Brains, and Experience (pp. 299317). Oxford: Oxford University Press.

Chatterjee, A., Thomas, A., Smith, S. E., \& Aguirre, G. K. (2009). The neural response to facial attractiveness. Neuropsychology, 23, 135-143.

Cochrane, A. L. (1972). Effectiveness and efficacy: Random reflections on health services. London: Nuffield Provincial Hospitals Trust.

Conklin, H. C. (1964). Ethnogenealogical methods. In W. H. Goodenough (Ed.), Explorations in Cultural Anthropology (pp. 25-55). New York: McGraw-Hill. 
Conklin, H. C. (1969). Lexicographical treatment of folk taxonomies. In Stephen A Tyler (Ed.) Cognitive Anthropology Readings (pp. 41- 66). New York Holt: Rinehart and Winston.

Creswell, J. W. (1998). Qualitative Inquiry and Research Design: Choosing Among Five Traditions. Thousand Oaks, CA: Sage.

Cunningham, M., Barbee, A., \& Philhower, C. (2002). Dimensions of facial physical attractiveness: The intersection of biology and culture. In G. Rhodes \& L. Zebrowitz (Eds.), Facial attractiveness. Evolutionary, cognitive, and social perspectives (pp. 193-238). Westport, CT: Ablex.

de Jong, T. \& Fergusson-Hessler, Monica G.M. (1996). Types and Qualities of knowledge. Educational Psychologist, 31(2), 105-113.

Durkheim, E. (1997). The Division of Labor in Society. Lewis A. Coser (Trans.). New York: Free Press.

Ellen, R. E., \& Reason, D. Eds. (1979). Classifications in their Social Context. London: Academic Press.

Eberhard, J. (2009). Brain Landscape: The Coexistence of Neuroscience and Architecture. New York: Oxford University Press.

Farah, M. (2000). The cognitive neuroscience of vision. Malden, MA: Blackwell Publishers.

Fechner, G. (1860). Elements of psychophysics (H. Adler, Trans.). New York: Holt, Rinehart and Winston, Inc.

Firestein, S. (2012). Ignorance: How It Drives Science. New York: Oxford University Press.

Firestein, S. (2012). http://www.npr.org/2012/06/01/154148658/why-ignorance-trumpsknowledge-in-scientific-pursuit. Retrieved on 27 July 2012.

Gardner, H. (1975). The shattered mind. The person after brain damage. New York: Alfred A. Knopf.

Gibson, J. J. (1977). The theory of affordances. In R. E. Shaw \& J. Bransford (Eds.), Perceiving, Acting and Knowing (pp. 67-82). Hillsdale, NJ: Lawrence Erlbaum Associates.

Gibson, J. J. (1979). The Ecological Approach to Visual Perception. Boston, MA: Houghton Mifflin.

Gibson, E. J. (2000a). Perceptual learning in development: some basic concepts. Ecol Psychol, 12(4), 295-302. doi:10.1207/ S15326969ECO1204_04

Gibson, E. J. (2000b). Where is the information for affordances? Ecol Psychol, 12(1), 53-56. doi:10.1207/S15326969ECO1201_5 
Gifford, R. (2002). Environmental Psychology: Principles and Practice (3rd ed.). Colville, WA: Optimal Books.

Greeno, J. G. (1994). Gibson's affordances. Psychological Review, 101 (2), 336-342. doi:10.1037/0033-295X.101.2.336.

Greeno, J. G. (1998). The situativity of knowing, learning, and research. American Psychologist, 53 (1), 5-26. doi:10.1037/0003-066X.53.1.5.

Groat, L. \& Wang, D. (2002). Architectural Research Methods. New York: Wiley.

Gutman, R. (1988). Architectural Practice: A Critical View. Princeton: Princeton Architectural Press.

Hall, E.T. (1959). The Silent Language, New York: Doubleday.

Hall, E.T. (1966). The Hidden Dimension, New York: Doubleday.

Hamilton, D. K. (2003). The four levels of evidence-based design practice. Healthcare Design, 3, 18-29.

Hamilton, D. K. (2004). Hypothesis and Measurement: Essential Steps Defining Evidence-Based Design. Healthcare Design, 4[Mar], 43-6.

Hamilton, K., \& Stichler, J. E. (2008). Evidence-Based Design: What is it? HERD- Healthcare Environment Research and Design Journal, 1(2), 3-4.

Hartson, H. R. (2003). Cognitive, Physical, and Perceptual Affordances in Interaction Design. Behavior and Information Technology, 22(5), 315-338.

Ishai, A., Fairhall, S., \& Pepperell, R. (2007). Perception, memory and aesthetics of indeterminate art. Brain Research Bulletin, 73, 319-324.

Jacobsen, T. (2006). Bridging the Arts and Sciences: A Framework for the Psychology of Aesthetics. Leonardo, 39(2), 155-162.

Joseph, A. (2006a). The Impact of the Environment on Infections in Healthcare Facilities. Issue Paper \#1. Concord, CA: The Center for Health Design.

Joseph, A. (2006b). The impact of light on outcomes in healthcare settings. Issue Paper \#2. Concord, CA: The Center for Health Design.

Joseph, A. (2007). The role of the physical and social environment in promoting health, safety, and effectiveness in the healthcare workplace. Issue Paper \#3. Concord, CA: The Center for Health Design.

Kannengiesser, U., \& Gero, J. S. (2012). A process framework of affordances in design. Design Issues,28(1), 50-62. 
Kahneman, D. (2012). http://dotearth.blogs.nytimes.com/2012/05/25/daniel-kahneman-on-thetrap-of-thinking-that-we-know/. Retrieved on 27 July 2012.

Kuhn, T. (1962). The Structure of Scientific Revolutions. Chicago: University of Chicago Press.

Larson, M. S. (1974). The Rise of Professionalism: A Sociological Analysis. Berkeley: University of California Press.

Latto, R. (1995). The brain of the beholder. In R. Gregory, J. Harris, P. Heard, \& D. Rose (Eds.), The Artful Eye (pp. 66-94). New York: Oxford University Press.

Lévi-Strauss, C. (1966). The Savage Mind. John Weightman, \& Doreen Weightman (Trans.). Chicago: University of Chicago Press.

Liberati, A., \& Vineis, P. (2004). Ethics, philosophy, and evidence based medicine. Journal of Medical Ethics, 30, 120-121.

Lintern, G. (2000). An affordance-based perspective on human- machine interface design. Ecol Psychol, 12(1), 65-69. doi: 10.1207/S15326969ECO1201_7

Livingstone, M. (2000). Is It Warm? Is It Real? Or Just Low Spatial Frequency?" Science, 290, 1299.

Livingstone, M. (2002). Vision and Art: The Biology of Seeing. New York: Harry N. Abrams.

Looker, P. (2008). Evidence-based design: Why the controversy? Retrieved on July 28, 2012, from http://www.mcmorrowreport.com/hfm/articles/ebd.asp

Low, S. M. (2003). Embodied Space(s): Anthropological Theories of Body, Space, and Culture. Space and Culture, 6(9), 9-18.

Maier, J. R. A., \& Fadel, G. M. (2009a). Affordance based design: A relational theory for design. Research in Engineering Design, 20(1), 13-27.

Maier, J. R. A., \& Fadel, G. M. (2009b). Affordance-based design methods for innovative design, redesign and reverse engineering. Research in Engineering Design, 20(4), 225-239.

Maier, J. R. A., Fadel, G. M., \& Batisto, D. (2009). An affordance based approach to architectural theory, design, and practice. Design Studies, 30, 393-414.

Malkin, J. (2008). A Visual Reference for Evidence-Based Design. Concord, CA: The Center for Health Design.

Martin, L. (1972). The grid as generator. In L. Martin \& L. March (Eds.), Urban space and structures (pp. 6-27). Cambridge: The University Press.

Martin, L., \& March, L., Eds. (1972). Urban space and structures, Cambridge: The University Press. 
McCue, G. M., \& William R. E. Jr. (1970). Creating the Human Environment. Urbana: University of Illinois Press.

McCullough, C. Ed. (2009). Evidence-Based Design for Healthcare Facilities. Indianapolis, IN: Sigma Theta Tau International.

Munn, N. (1996). Excluded spaces: The figure in the Australian Aboriginal landscape. Critical Inquiry, 22, 446-465.

Murphy, R. R. (1999). Case studies of applying Gibson's ecological approach to mobile robots. IEEE Transactions on Systems, Man, and Cybernetics, Part A: Systems and Humans, 29(1), 105111.

Norman, D. A. (2002). The Design of Everyday Things. New York: Basic Books.

Norman, D. A. (1999, May/June). Affordances, conventions, and design. Interactions, 38-42.

Nuffield Provincial Hospitals Trust, \& The University of Bristol (1956). Studies in the functions and design of hospitals. Nuffield Provincial Hospitals Trust. Oxford, UK: The University Press.

Pandya,V. (1990).Movement and space: Andamanese cartography. American Ethnologist, 17(4), 775-797.

Pickering, J. (2000). On the proper treatment of affordance: formality or mutuality. Ecol Psychol, 12(1), 71-77. doi:10.1207/S15326969 ECO1201_8

Popper, K. (1963). Conjectures and Refutations: The Growth of Scientific Knowledge. London: Routledge Classics.

Rashid, M. and Zimring, C. (2008). A Review of the Empirical Literature on the Relationships between Indoor Environment and Stress in Healthcare and Office Settings: Problems and Prospects of Sharing Evidence, Environment and Behavior, 40(3), 151-190.

Ramachandran, V. S., \& Hirstein, W. (1999). The science of art: A neurological theory of aesthetic experience. Journal of Consciousness Studies, 6, 15-51.

Saarni, S., \& Gylling, H. (2004). Evidence based medicine guidelines: A solution to rationing or politics disguised as science? Journal of Medical Ethics, 30, 171-175.

Sheridan, J. G., \& Kortuem, G. (2006). Affordance-based design of physical interfaces for ubiquitous environments. In: Proceedings of Ubiquitous Computing Systems, Third International Symposium, UCS 2006, Seoul, Korea. LNCS 4239 (pp. 183-199). Berlin: Springer.

Shimamura, A. P. \& Palmer, S. E. Eds. (2012). Aesthetic Science: Connecting Minds, Brains, and Experience. Oxford: Oxford University Press.

Sitaras, N. M. (Ed.) (2012). Evidence Based Medicine - Closer to Patients or Scientists? Rijeka, Croatia: InTech. Retrieved on November 20, 2012 from www.intechopen.com 
Stamps, A. E. III (2000). Psychology and the Aesthetics of the Built Environment. Boston, MA: Kluwer Academic Publishers.

Stamps, A. E. III (1998). Measures of architectural mass: form vague Impressions to Definite design Features. Environment and Plannign B: Planning and Design, 25, 825-836.

Stankos, M., \& Scharwz, B. (2007). Evidence-Based Design in Healthcare: A Theoretical Dilemma. IDRP Interdisciplinary Design Research e-Journal, 1(1), 1-15.

Stoffregen, T. A. (2000). Affordances and events. Ecol Psychol, 12(1), 1-28. doi:10.1207/S15326969ECO1201_1

Thompson, D. R., Hamilton, D. K., Cadenhead, C. D. et al. (2012). Guidelines for Intensive Care Unit Design. Crit Care Med 40(5), 1586-1600.

Thompson J. D., \& Goldin, G. (1975). The Hospital: A Social and Architectural History. New Haven and London: Yale University Press.

Tonelli, M.R. (2001). The limits of evidence-based medicine. Respiratory Care, 46(12), 14351440.

Ulrich, R.S., Zimring, C., Zhu, X., et al. (2008). A review of the literature on evidence-based healthcare design, HERD - Healthcare Environment Research and Design Journal, 2008, 1(3), 61-125.

Ulrich, R., C. Zimring, et al. (2004). The Role of the Physical Environment in the Hospital of the 21st Century: A Once-in-a-Lifetime Opportunity. Concord, CA: Center for Health Design.

Unwin, R. (1912). Nothing Gained by Overcrowding. Orchard House, Westminster: P. S. King \& Son.

You, H., \& Chen, K. (2007). Applications of affordance and semantics in product design. Design Studies, 28(1), 23-38. doi:10.1016/j.destud.2006.07.002

Zeisel, J. (2005). Environment/Behavior/Neuroscience. In Inquiry by Design (pp. 355-380). New York: W. W. Norton.

Zeki, S. (1999a). Art and the brain. Journal of Consciousness Studies, 6, 76-96.

Zeki, S. (1999b). Inner vision: An exploration of art and the brain. New York: Oxford University Press. 